\title{
Use of Zygomatic Implants for Atrophic Maxilla Rehabilitation - A Clinical Case Report of Unilateral Zygomatic Implant
}

\author{
García Lozada $V^{*}$
}

DDS Central University of Venezuela, MSc University of Lleida, Spain

Department of Oral and Maxillofacial Implantology, Cibumax, Spain

*Corresponding author: Vladimir García Lozada, DDS, Central University of Venezuela, MSc University of Lleida; Department of Oral and Maxillofacial Implantology, Cibumax, Spain, E-mail: vleogl@hotmail.com

Citation: García Lozada V (2018) Use of Zygomatic Implants for Atrophic Maxilla Rehabilitation - A Clinical Case Report of Unilateral Zygomatic Implant. J Oral Health Dent 2: 105

Article history: Received: 21 November 2017, Accepted: 20 Febraury 2018, Published: 22 Febraury 2018

\begin{abstract}
Traditionally the atrophic maxilla has been treated with autologous bone grafts, alloplastic grafts, and techniques such as sinus lift. Now a day the use of zygomatic implant allows us to make a prosthetic rehabilitation of the atrophic maxilla without bone grafts need and the possibility of immediate loading protheses to patients. In this work we propose the use a unilateral zygomatic implant in combination with conventional implants and immediate loading prostheses to solve a partially edentulous case.
\end{abstract}

Keywords: Unilateral zygomatic implant; Atrophic maxilla; Immediate loading

\section{Introduction}

At present, there are still many doubts about the benevolence of the routine use of sinus graft material prior to implant placement. Most of them are caused because most of the works that describe these techniques suffer from: clear criteria in terms of basic definitions, such as success or failure of the implant; description of the starting bone height; standardized radiolographs. The publications are usually retrospective and frequently the cli-nical and biotechnological concepts are mixed producing the confusion of the reader [1].

After the loss of the alveolar process, the maxilla suffers progressive bone loss in both width and height, which usually limits the placement of implants in the posterior region. For decades, the atrophy of the maxillary process has been treated by large grafts from the iliac crest or calota in the form of onlays, in combination or not with a segmental osteotomy type Lefort; or by sinus inlays. Clinical studies with a long follow-up time reveal disparity in the survival of the implants after these procedures; Success depends to a large extent on the amount of preexisting bone in the residual bone crest and on the appearance of complications derived from the grafted area [2-7].

The use of zygomatic implants allows the rehabilitation of patients with maxillary bone atrophy, offering a very satisfactory function and aesthetics, returning them to a normal social life by simplifying treatment, reducing costs, execution time and lower morbidity for patients, because it is a less invasive surgery compared with maxillary reconstructions with autologous grafts [2].

Zygomatic implants were used for the first time by Professor P-I Branemark in 1987 for the rehabilitation of cancer patients who underwent maxillectomies or tumor resections, trauma and congenital defects $[1,8,9]$.

The use of zygomaticmalar bone as an anchorage for oral implants was originally described by P-I Branemark and proposed by Aparicio, et al. in 1993 as an excellent alternative in the partial rehabilitation of the maxilla [1,2].

The zygomatic implant is characterized by being autoroscable with lengths ranging from 30 to $52.5 \mathrm{~mm}$ with $2.5 \mathrm{~mm}$ intervals $[8$, 10-12].

These lengths are justified because this implant will be anchored in the region of the alveolar process, crossing the maxillary sinus to the body of the zygoma bone. These variations of the lengths are given by their wide trajectory and variable travel depending on the anatomical characteristics of each patient $[8,9]$.

Zygomatic implants can be loaded immediately because their length allows bone anchorage of one or more cortical bone, therefore greater bone contact with the implant surface and stability; the head of the implants is angled and allows the screws to be placed parallel to each other, articulating the prosthesis with the axial axis of the implant; the intraosseous placement of the implants goes 
in an angled direction from $43.8^{\circ}$ to $50.6^{\circ}$ from palatal to the zygomatic bone. It does not require prosthetic techniques in addition to the traditional ones of conventional implants [13].

As with conventional implants, the preparation of the surgical osteotomies are made through a successive lengthening using long drills, these drills have a socket that allows its coupling to a straight 20: 1 reductive piece that is adapted on the handle of the micromotor. Contra-angle is not used due to the nature of the implant and the surgical access [9].

The first drill of the system is the spherical one that has a diameter of $2.9 \mathrm{~mm}$. The successive drills are: twist of $2.9 \mathrm{~mm}$, pilot of 2.9-3.5 $\mathrm{mm}$ and twist of $3.5 \mathrm{~mm}$. All of them are driven at high speed at $2000 \mathrm{rpm}$ [9].

The rest of the instruments are the probes that will indicate the direction of the perforations and the exact length of the implant to be used. There are two types of probe, the $2.0 \mathrm{~mm}$ probe that has a hook at its active tip with all the marking of the lengths of the implants. It greatly facilitates the identification of the available bone quality and quantity as well as the length of the fixation. The thicker $3.0 \mathrm{~mm}$ probe offers the final forecast of the length of the implant and the correct direction of the implant to be inserted. The drills are quite long and therefore during their use can cause lesions of the surrounding soft tissues, mainly the lips. For this reason, perforations require the use of instruments for the protection of these structures [9].

The insertion of the implant is done through the use of a zygomatic installation driver mounted on the zygoma piece or through the specific hand driver for this technique.

\section{Clinical case}

Female patient, 68 years old without major systemic disease, only slight hypertension but properly controlled. She presented absence of the pieces \#22,23,24, 25 of the upper jaw and pieces \#26, 27 with periodontal disease and mobility as well as being extruded for not having antagonistic pieces for occlusion, causing a decompensated bite with clear clinical symptoms of bruxism. She reported problems with poor chewing function (Figure 1 and 2).
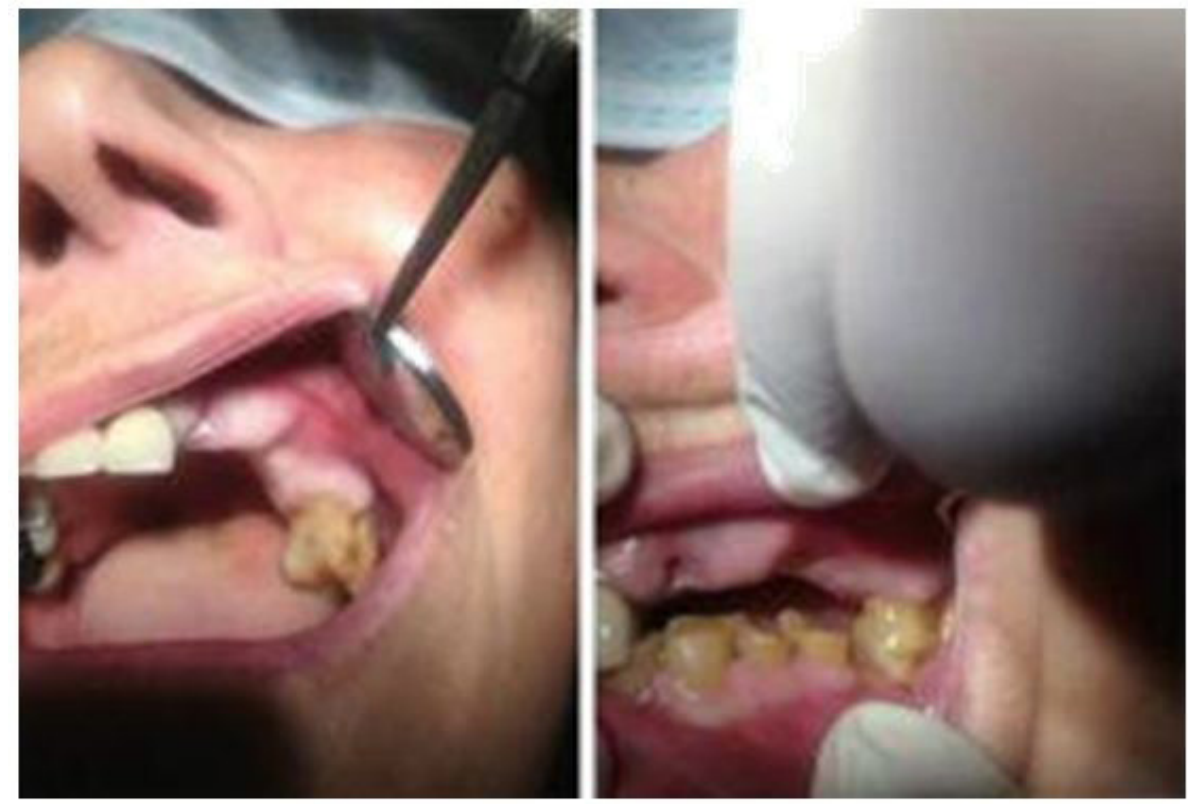

Figure 1: Pre-operative clinical pictures

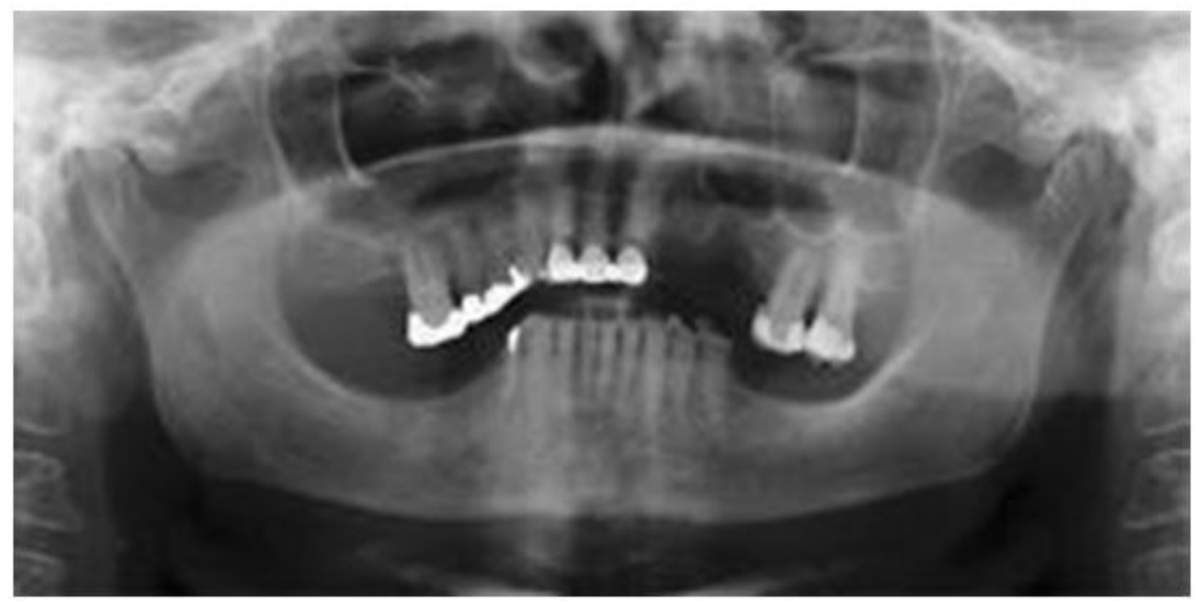

Figure 2: Pre-operative radiograph 
The same went to the Center of Dental Specialties to the service of Oral Surgery and Oral Implantology Cibumax for examination, diagnosis and resolution of clinical problems.

After the clinical, radiographic examination and definition of the treatment plan to be performed, a conscious sedation was performed with midazolam, installation of the surgical fields and infiltration with articaine anesthetic for nerve block.

The extractions of \#26, 27 were performed with their proper debridement and bone regularization, the left zygomatic hemi-arch flap was lifted and a small lateral window in the maxillary sinus was removed, together with the detachment of the schneiderian membrane to determine the correct orientation of the zygomatic implant in the malar bone, we continue with the drilling sequence for the osteotomy of the zygomatic implant and the insertion of the same one, followed by the osteotomies for the insertion of two anterior conventional implants in position \#22, 23.

A $4 \times 45 \mathrm{~mm}$ Neodent ${ }^{\circledR}$ zygomatic implant was installed, in the left hemiarch in position \#25 and two conventional implants; a TitamaxEX $4 \times 17 \mathrm{~mm}$ Neodent ${ }^{\circledR}$ implant in position \#22 and a TitamaxEX $4 \times 15 \mathrm{~mm}$ Neodent ${ }^{\circledR}$ implant in position \#23 (Figure 3 and 4).

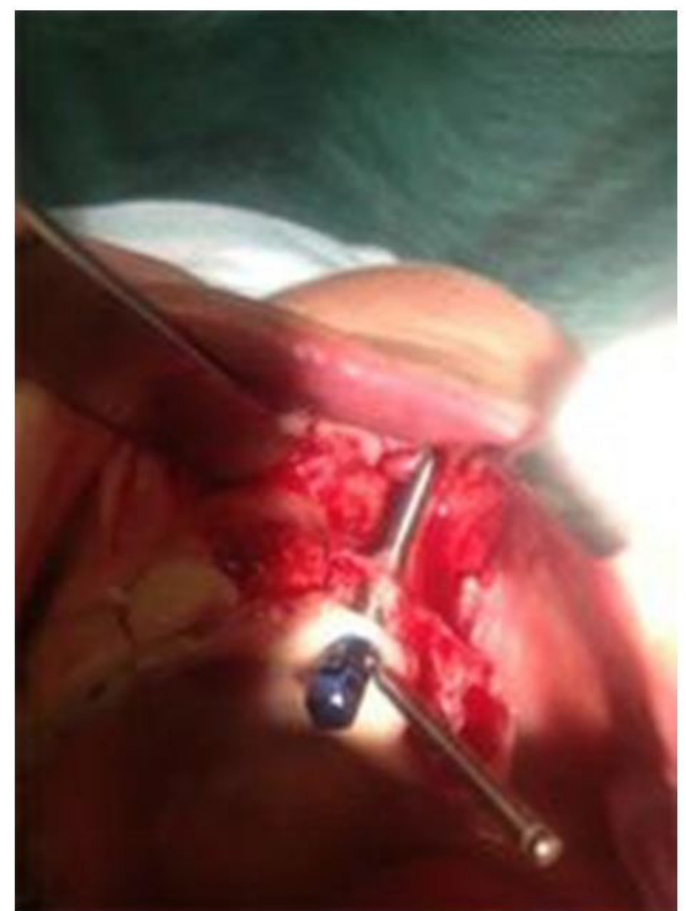

Figure 3: Clinical picture of zygomatic implant in \#25 position.

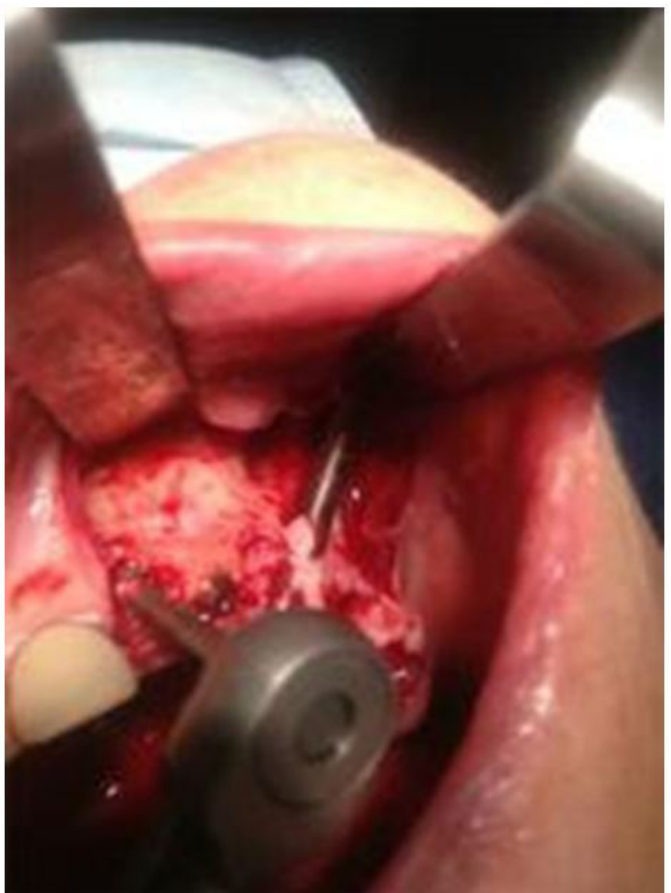

Figure 4: Clinical picture of conventional implants in \#22 \#23 position 
When a good insertion torque value of $65 \mathrm{Nw}$ was obtained both from the zygomatic implant and from conventional implants, straight multiunit abutments Neodent ${ }^{\circledR}$ were placed for the preparation of a provisional immediate load prostheses from \#22 to 25 , continuing with the closure flap sutures with black silk 000 (Figure 5).

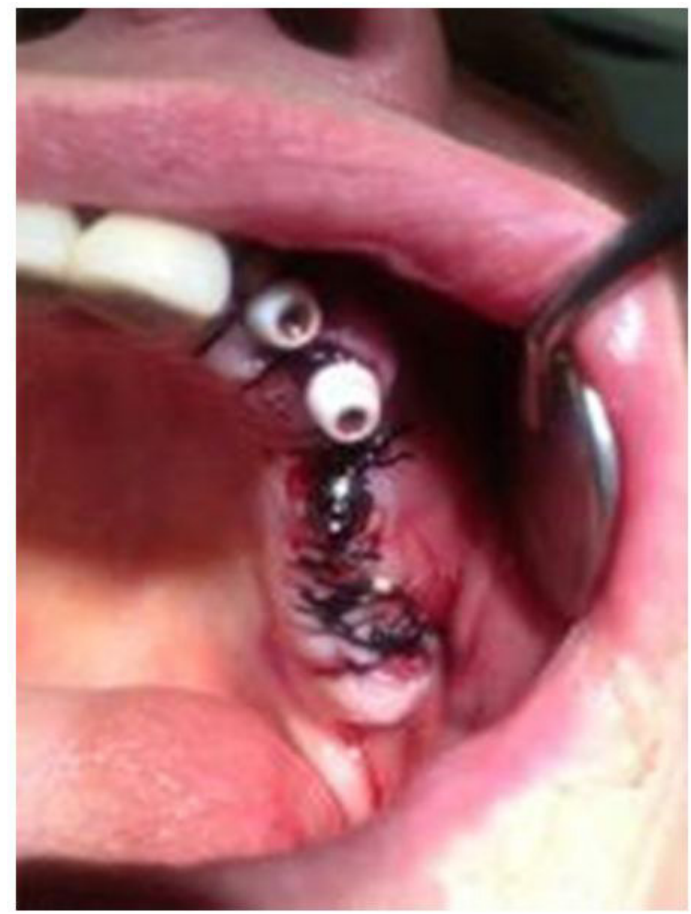

Figure 5: Clinical picture of multiunit abutments placed and sutures

Impressions, bite registration tests and tooth color were taken for the preparation of the provisional immediate load prosthesis to be installed the same day of the implant surgery, and to do its respective postoperative radiographic record (Figure 6).

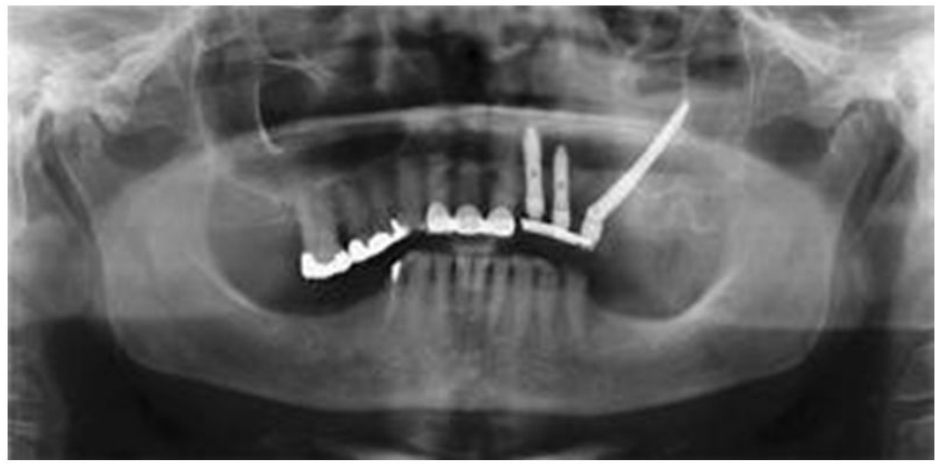

Figure 6: Post-operative radiograph

The surgical procedure was performed without complications, achieving a good primary stability of the implants to be able to perform the provisional immediate load prothesis and thus the patient reincorporate to their social life as soon as possible getting a comfort and aesthetics quite pleasant.

The patient came to the clinic at 7 days for adjustment of the immediate loading prosthesis and removal of the sutures, without presenting greater signs of inflammation and with a fairly rapid recovery (Figure 7).
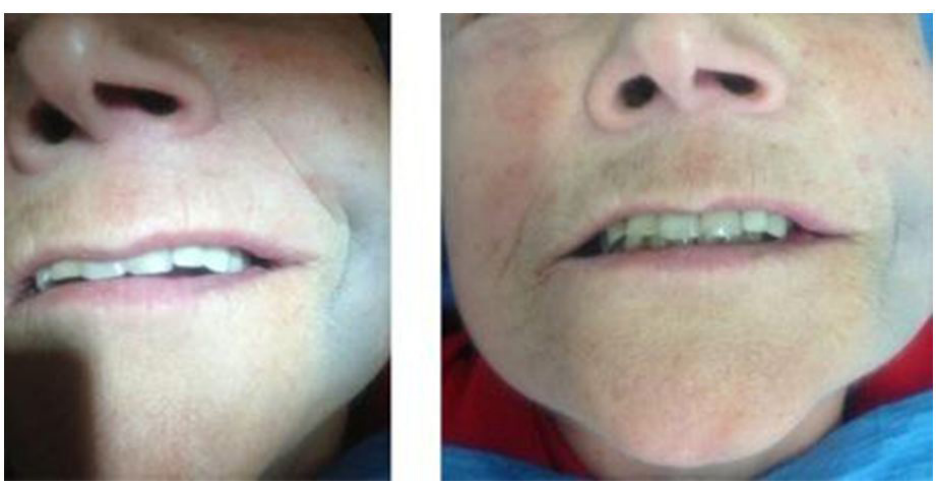

Figure 7: Clinical pictures post-operative 7 days after 
In the control at 12 month post-surgery we take a panoramic radiograph, and we can see the optimal bone-implants healing and osseointegration with the final prosthesis, and with any problem, all the treatment its stable and with good results (Figure 8).

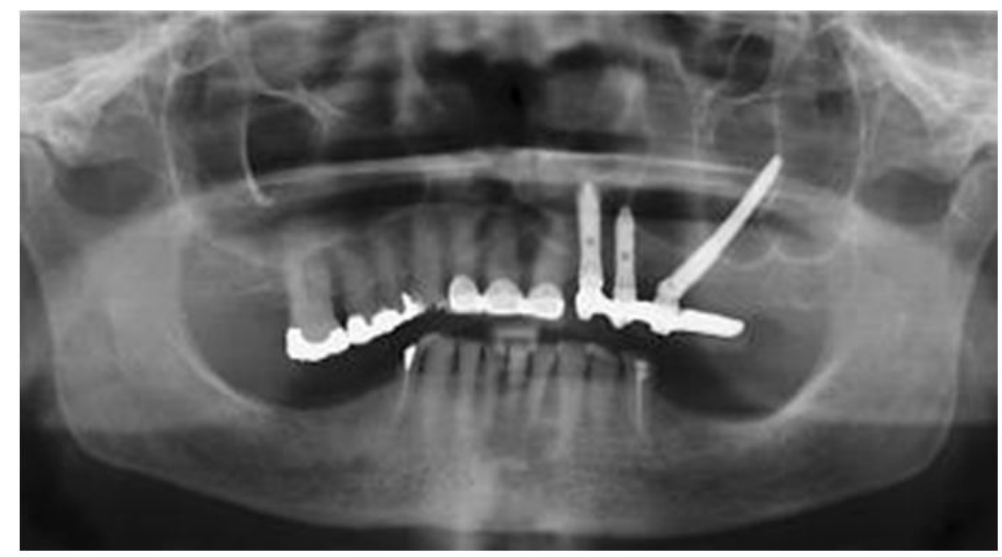

Figure 8: Panoramic radiograph 12 month post-surgery

\section{Discussion}

Brånemark et al reported the 10-year results of 56 zygomatic implants in 28 patients. The authors conducted regular clinical and radiographic examinations of this group of patients and concluded that zygomatic implants were predictable, with a long- term survival rate exceeding $94.3 \%$ [14].

The zygomatic implant is derived from the remote implant anchorage concept developed by Parel, et al. [15].

After more than 12 years of follow-up, a high survival rate of $97 \%$ for the zygomatic implant has been demonstrated [15,16].

Furthermore, Malevezand Bedrossian report a 100\% survival rate after 48 and 36 months, respectively, using 2-stage protocols, and a $98 \%$ survival rate was reported in a multicenter study at 16 clinics, after 1 year of follow-up [17-19].

For these reasons, zygomatic implants represent a good alternative for the rehabilitation of the atrophied maxilla, the same good results were appreciated in this case, even having a unilateral approach and with immediate loading.

\section{Conclusion}

Both the literature and our experience, shows that the technique with zygomatic implants give good clinical results for the rehabilitation of atrophic jaws, with the added possibility of immediate loading of them and thus return the chewing and aesthetic function in a faster way to the use of bone grafts.

Therefore zygomatic implants are of great help in the prosthetic rehabilitation of the severe atrophic jaws in both partially edentulous and total edentulous patients, being a great tool for the surgeon-implantologist when performing rehabilitations without the use of grafts and with load or immediate function. The technique for the placement of zygomatic implants should be considered as a major surgical procedure and should have appropriate training.

\section{References}

1. Aparicio Magallon C, OuazzanI W, Aparicio Magallon E (2001) Implantes Zigomáticos en rehabilitación del maxilar superior atrófico. Ciencia y práctica Maxillaris 30-6.

2. Aparicio Magallon C, Soto Yarritu R (2008) Que indicaciones tienen y que resultados nos ofrece los implantes cigomáticos. Cient Dent 5: 69-80.

3. Garcia Lozada V (2015) Utilización de implantes cigomáticos para la rehabilitación del maxilar atrófico. A propósito de un caso clínico. Revista Maxillaris 188: 92-103.

4. Becktor JP, Hallstroem H, Isaksson S, Sennerby L (2008) The use of particulate bone grafts from the mandible for maxillary sinus floor augmentation before placement of surface-modified implants: results from bone grafting to delivery of the final fixed prosthesis. J Oral Maxillofac Surg 66: 780-6.

5. Collins TA, Brown GK, Johnson N, Massey JA, Nunn BD (1995) Team management of atrophic edentulous with autogenous inlay, veneer, and split grafts and endosseous implants: case reports. Quintessence Int26: 79-93.

6. Graziani F, Dono N, Needleman N, Gabriele M, Tonetti M (2004) Comparison of implant survival following sinus floor augmentation procedures with implants placed in the pristine posterior maxillary bone: a systematic review. Clin Oral Implants Res 15: 677-82.

7. Hallman M, Hedin M, Sennerby L, Lundgren S (2002) A prospective 1-year clinical and radiographic study of implants placed after maxillary sinus floor augmentation with bovine hydroxyapatite and autogenous bone. J Oral Maxillofac Surg 60: 277-84.

8. Aparicio C (2008) Zygomatic implants the anatomy-guided approach. London: Quintessence.

9. Nary filho H, Marques padovan L (2008) Zygomatic Fixation - An Alternative to Rehabilitation in Atrophic Jaws (Fixacao Zigomática Uma alternativa para Re Habilitacao Em Maxilas Atróficas). Sao Paolo: Santos.

10. Balshi T, Wolfinger G (2003) Quadruple zygomatic implant support for retreatment of resorbed iliac crest bone graft transplant. Implant Dentistry 1: 47-52. 
11. Bedrossian E, Stumpel L, Beckele M (2002) The zygomatic implant: preliminary data on treatment of severely reabsorbed maxillae. A clinical report. Int J Oral Maxillofac Implants 17: 861-5.

12. Malevez C (2003) Use of zygomatic implants to deal with resorbed posterior maxillae. Periodontol 2000 33: 82-9.

13. Guerrero C, SabogaL A (2011) Implantes Cigomáticos Atlas de Cirugía y Prótesis. Madrid: Ripano.

14. Brånemark PI, Gröndahl K, Öhrnell L-O (2004) The zygoma option.Clinical procedure and long-term results.Scand J Plast Reconstr Surg Hand Surg 38: 70-85.

15. Parel SM, Branemark PI, Ohrnell LO, Svensson B (2001) Remote implant anchorage for the rehabilitation of maxillary defects. J Prosthet Dent 86: $377-81$.

16. Bedrossian E, Stumpel LJ (2001) Immediate stabilization at stage II of zygomaticim-plants: rationale and technique. J Prosthet Dent 86: 10-4.

17. Malevez C, Abarca M, Durdu F, Daelemans P (2004) Clinical outcome of 103 consecutive zygomatic implants: a 6-48 months follow-up study. Clin Oral Implants Res 15: 18-22.

18. Bedrossian E, Stumpel L, Beckely ML, Indresano T (2002) The zygomatic implant: pre-liminary data on treatment of severely resorbed maxillae. A clinical report. Int J Oral Maxillofac Implants 17: 861-5.

19. Malevez C, Daelemans P, Adriaenssens P, Durdu F (2003) Use of zygomatic implants to deal with resorbed posterior maxillae. Periodontol 2000 33: $82-9$. 